\title{
A Novel L-Z Source Inverter with Improving of Classical Z Source Inverter
}

\author{
Dubasi Nirosha \\ Aditya Engineering College, Approved by AICTE, Permanently Affiliated to JNTUK \& NBA Accredited, Recognized by UGC under the \\ sections 2(f) \& 12(B) of the UGC act 1956
}

\begin{abstract}
On the basis of the classical ZSI(Z source inverter) provides a common ground for the DC source and Inverter, and avoids the disadvantages caused by capacitor in the Classical ZSI and SL-ZSI, especially in prohibiting the inrush current at startup. The inverter uses a unique inductor and diode network for boosting its output voltage. This inverter can improve the boost factor through adjusting shoot-through duty ratio and increasing the number of inductors. This thesis presents a novel ZSI uses a unique inductor and diode network with reducing inrush current. The working principle experimental results are analyzed in detail.
\end{abstract}

Keywords: Inrush Current, Resonance, Inductor, Power converter

\section{Introduction}

Z-source inverter is a type of power inverter, a circuit that converts direct current to alternating current. It functions as a buck-boost inverter without making use of Dc-Dc Converter Bridge due to its unique circuit topology. Impedance Zsource networks provide an efficient means of power conversion between source and load in a wide range of electric power conversion applications. The DC source is not always constant, such as a fuel cell, photo voltaic array and during voltage sags etc. a DC/DC boost converter is often needed to boost the DC voltage to meet the required output voltage or to allow the nominal operating point to be favorably located. This increases the system complexity and is desirable to eliminate if possible. This problem can be overcome by Z-source inverters in single-stage operations.

In recent years, various Z-source inverter (ZSI) topologies have been presented in numerous diversified studies[1-13]. Some of the studies are focused on applications, modeling, controls and modulation strategies [1-9], whereas others are focused on the development of new topologies [10-13].

The ZSIs accomplish a single-stage power conversion with buck-boost capabilities. In ZSIs, both of the power switches in a leg can be turned on at the same time and thereby eliminate the dead time. This significantly improves the reliability and reduces the output waveform distortion. Fig. 1(a) shows the classical ZSI in which the two-port impedance network couples the main inverter circuit to the dc source. In order to overcome the shortcomings of the classical ZSI, the quasi-ZSI (QZSI) shown in Fig. 1(b) and SL-ZSI shown in Fig. 1(c) $[10,11,12]$. Despite the aforementioned merits, the aforementioned Z-source inverter topologies also show the following drawbacks: 1) capacitors are used in the Z-source network, thus high-voltage or large capacity capacitors should be used, which may result in large volume, cost expensive, and reducing the life span of system; 2) it cannot suppress the inrush current and the resonance introduced by Z-source capacitors and inductors at startup, thus causing the voltage and current surge, which may destroy the devices; 3) it regulates boost factor only by adjusting the shoot-through duty ratio. To solve the aforesaid drawbacks in aforementioned Z-source inverter, a new Z- source inverter topology is presented with no capacitor and reducing inherent inrush current limitation at startup. It can suppress the resonance thoroughly by removing capacitor and improve the efficiency of power supply. The operation principle and comparison with the classical ZSI and SL- ZSI reveal the merits of the proposed topology, and are also verified in both simulation and experiment.

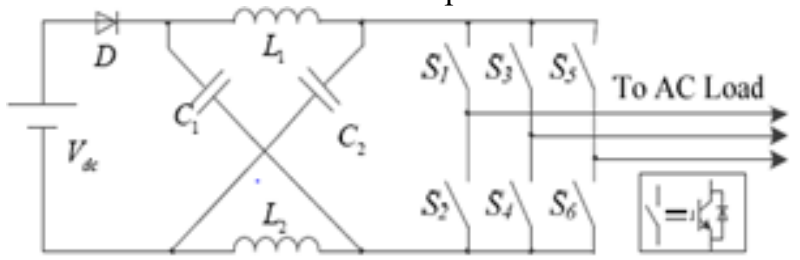

a.the classical ZSI

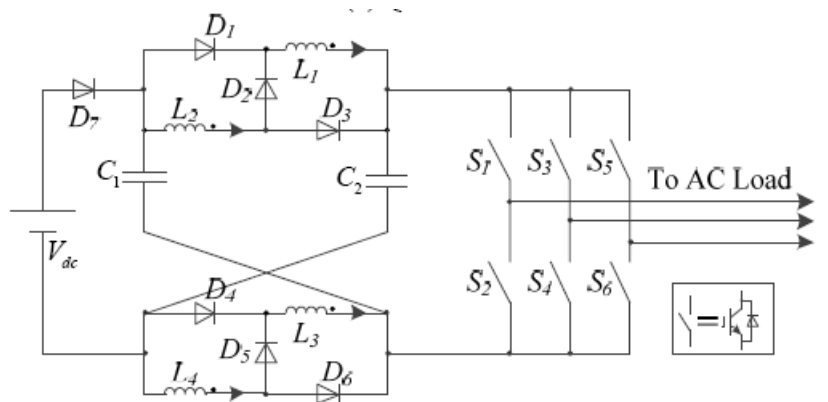

(b) SL-ZSI

Figure 1: Conventional impedance- network inverter topologies

\section{L- Z- Source Inverter}

Different to the original ZSI, the proposed inverter has no capacitor, and is composed of two inductors (L1, L2, and $\mathrm{L} 1=\mathrm{L} 2)$, and three diodes (D1, D2, and D3), as shown in Fig.2. The combination of L2- L3- D1- D2- D3 acts as a switched inductor cell [12- 13]. The proposed topology provides inrush current suppression, unlike the traditional topologies, because no current flows to the main circuit at startup. The proposed topology also provides a common ground for the source and inverter. 


\section{International Journal of Science and Research (IJSR) \\ ISSN (Online): 2319-7064}

Index Copernicus Value (2013): 6.14 | Impact Factor (2014): 5.611

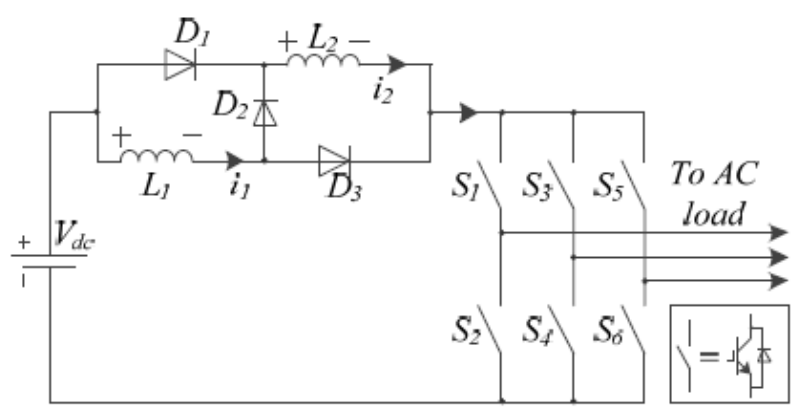

Figure 2: L- ZSI with two inductors.

\section{A. Operation Principles}

Unlike the traditional ZSIs, L- ZSI just has shoot- through zero states besides the traditional six active states. The operating principles of the proposed inverter are also similar to those of the classical ZSI. For the purpose of analysis, the operating states are simplified into shoot-through and non shoot-through states. Fig. 3 shows the equivalent circuits of L- ZSI.

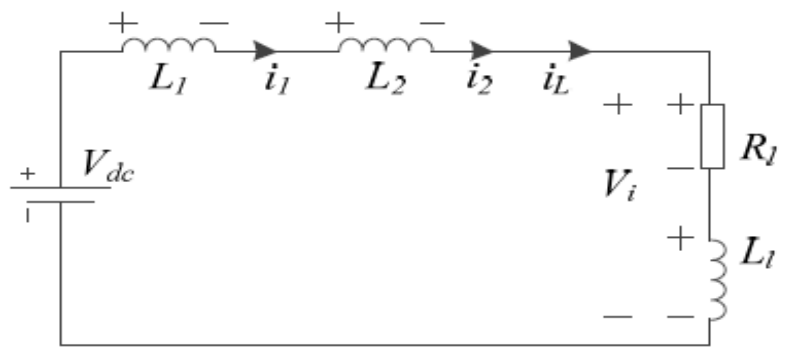

(a)

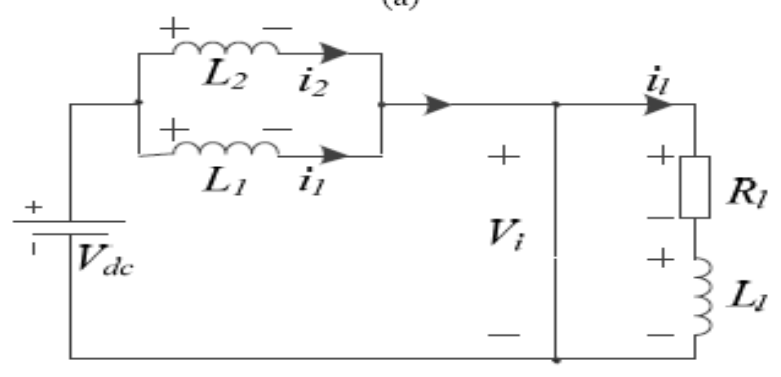

(b)

Figure 3: Operating states: (a) nonshoot-through and (b) shoot-through state.

In the nonshoot- through state, as shown in Fig. 2, D2 is on, While D1 and D3 are off. $L 1$ and $L 2(L 1=L 2=L)$ are connected In series. $L 1$ and $L 2$ transfer energy from the dc voltage source To the main circuit, and the equivalent circuit is shown in Fig. 3(a). The corresponding voltages across $L 1$ and $L 2$ in this state are $V$ a nonshoot and $V b$ nonshoot, respectively. Thereby, (1) and (2) can be contained.

$$
\begin{aligned}
& V_{a_{\text {nons hoot }}}+V_{b_{-} \text {nons hoot }}+V_{l}=V_{d}
\end{aligned}
$$

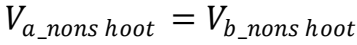

From (1) \& (2) we get, (3) \& (4),

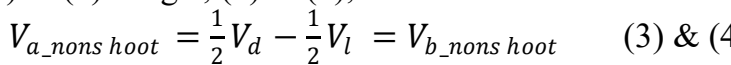

Where $V_{d}$ is the DC source; $V_{l}$ is the de link voltage.
Where $V d$ is the DC source; $\mathrm{Vl}$ is the de link voltage. In the shoot-through state, as shown in Fig. 2, the inverter side is shorted by both the upper and lower switching devices of any phase leg. During the shoot-through state, D2 is off, while $D 1$ and $D 3$ are on. $L 1$ and $L 2$ are connected in parallel, and inductors $L 1$ and $L 2$ store energy. The equivalent circuit is shown in Fig. 3(b). The corresponding voltages across $L 1$ and $L 2$ in this state are $V 1$ and $V 2$, respectively, and (5) is obtained

$$
V_{a}=V_{b}=V_{d}
$$

Applying the volt-second balance principle to $L 1$ and $L 2$, (6), (7), (8) and (9) can be obtained from (3), (4), and (5).

$$
\begin{gathered}
V_{l}=\frac{1+D}{1-D} V_{d} \\
B=\frac{1+D}{1-D} \\
I_{L}=I_{1}=I_{2}=D\left(2 L+L_{l}\right)+L(1-D) / R_{l} L(1-D) V_{d c} \\
I_{l}=\frac{(1+D) V_{d}}{R l}
\end{gathered}
$$

Where $B$ is the boost factor; IL is the inductor current; IL is the load current; D is shoot-through duty cycle; I1 and I2 are current of $L_{1}$ and $L_{2}$, respectively; Rl is load resistance; $L_{1}$ is load inductance. When $L_{l}=0$, then load is resistive.

$$
I_{L}=I_{a}=I_{b}=1+D / R_{l}(1-D) V_{d}
$$

\section{A. Boost Ability and Stress Comparison}

Different control and load conditions provide varied stresses of impedance-type power inverters. For comparison, the proposed L- ZSI, SL-ZSI, and the classical ZSI are simplified, as shown in Fig. 6. The ac side circuit is represented by its simplified equivalent dc load [20]. An resistive load impedance $(R l)$ connects directly in parallel with active switch $S$, where $i l$ and $v l$ are the instantaneous load current and voltage.

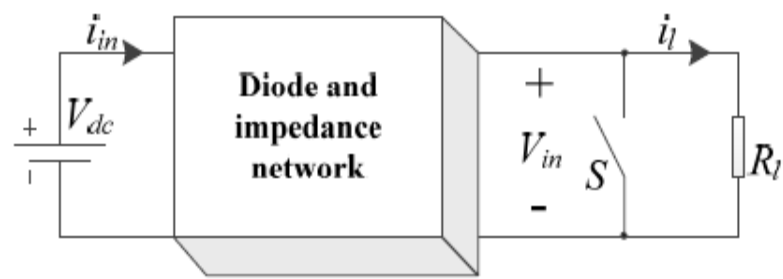

Figure 4: Simplified and unified equivalent circuit of impedance-type power inverters (i.e., L- ZSI, SL- ZSI, and the classical ZSI).

Using the steady-state analysis method and the maximum boost control method [15] for Fig. 6, we obtain the voltage and current stresses on the main components, such as $L$ and $C$. Tab. 1 compares the governing equations of the proposed L-ZSI, SL-ZSI, and the classical ZSI with the same $D$ and $V d$. 


\section{International Journal of Science and Research (IJSR) ISSN (Online): 2319-7064}

Index Copernicus Value (2013): 6.14 | Impact Factor (2014): 5.611

Table 1: Stress Comparison in the Case of the Same $D$ AND $V d$

\begin{tabular}{|c|c|c|c|}
\hline & SL-ZSI & classical ZSI & L-ZSI \\
\hline$B$ & $(1+\mathrm{D}) /(1-3 \mathrm{D})$ & $1 /(1-2 \mathrm{D})$ & $\frac{1+(n-1) D}{1-D}$ \\
\hline$V_{c}$ & $(1+\mathrm{D}) V_{d c} /(1-3 \mathrm{D})$ & $\frac{(1-\mathrm{D}) V_{d c}}{(1-2 \mathrm{D})}$ & 0 \\
\hline$V_{s}$ & $(1+\mathrm{D}) V_{d c} /(1-3 \mathrm{D})$ & $V_{d c} /(1-2 \mathrm{D})$ & $\frac{1+(n-1) D}{1-D} V_{d c}$ \\
\hline$I_{l}$ & $\frac{(1-\mathrm{D})(1+\mathrm{D})}{(1-3 \mathrm{D})} \frac{V_{d c}}{R_{l}}$ & $\frac{(1-\mathrm{D})}{(1-2 \mathrm{D})} \frac{V_{d c}}{R_{l}}$ & $\frac{1+(n-1) D}{R_{l}} V_{d c}$ \\
\hline$I_{L}$ & $\frac{(1-\mathrm{D})^{2}(1+\mathrm{D})}{(1-3 \mathrm{D})^{2}} \frac{V_{d c}}{R_{l}}$ & $\frac{(1-\mathrm{D})^{2}}{(1-2 \mathrm{D})^{2}} \frac{V_{d c}}{R_{l}}$ & $\frac{1+(n-1) D}{R_{l}(1-D)} V_{d c}$ \\
\hline
\end{tabular}

(Where $V c$ is capacitor voltage in Z-source network, and $V s$ is voltage stress of switching device.)

Compared with the classical ZSI and SL-ZSI, the proposed inverter can increase the voltage boost inversion ability through adjusting short shoot-through duty ratio or the number of inductor as shown in Fig.7. From Fig.7, it can be seen that voltage gain is increased with the increasing of shoot-through Duty ratio and the increasing of the number of inductors.

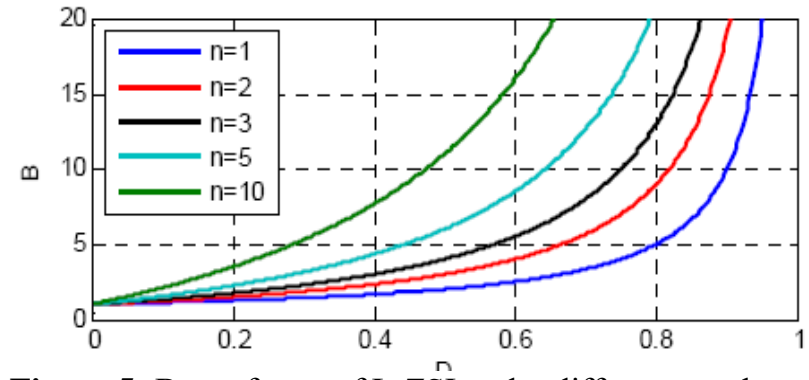

Figure 5: Boost factor of L-ZSI under different number of inductor

Fig. 6 shows the boost factor comparison among the classical ZSI, SL-ZSI and L-ZSI. In Fig.8, through adjusting the number of inductors, the boost factor of L-ZSI can be larger than that of SL-ZSI and the classical ZSI with short shootthrough zero states. Average value for boost factor change rate of L-ZSI is far less than that of SL-ZSI and the classical ZSI. This characteristic makes the boost factor change of LZSI is not very large, when the shoot-through duty ratio is changed. This characteristic also makes the control of L-ZSI is easier than that of SL-ZSI and the classical ZSI, when the shoot-through duty ratio is near 0.3 for SL-ZSI and near 0.5 for classical ZSI.

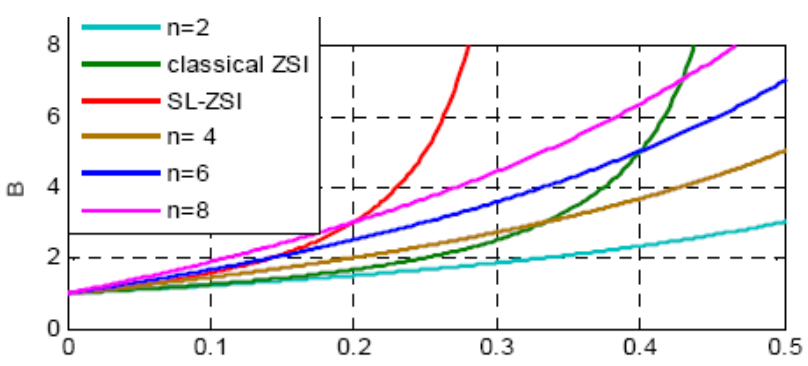

Figure 6: Boost factor comparison for L-ZSI, SL-ZSI and the classical ZSI
Since there is no capacitor in L-ZSI, capacitor voltage stress is zero. In SL-ZSI and the classical ZSI, capacitor voltage stress is increased with the increasing of voltage gain.

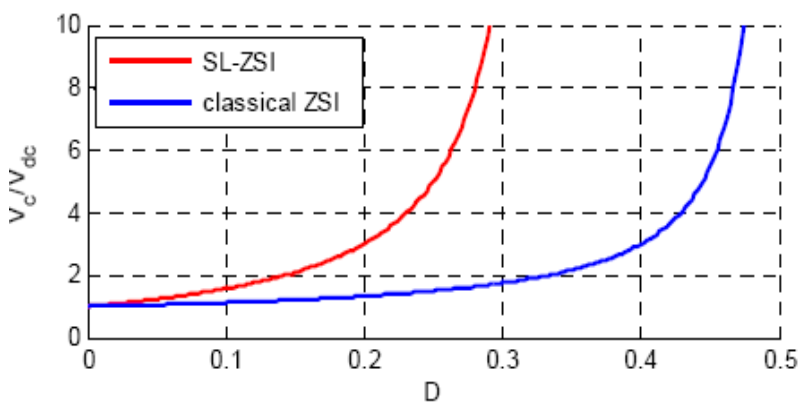

Figure 7: Capacitor voltage stress for SL-ZSI and the classical ZSI

In classical ZSI, SL-ZSI, and L-ZSI, the voltage stress Vs across the switches is just determined by dc link voltage $V d c$ as shown in Tab.1, and Fig.10 shows the switching device voltage stress curves. So, the voltage stress $V s$ is the same in classical ZSI, SL-ZSI, and L-ZSI with same boost factor. That is to say the voltage stress $V s$ is also the same in classical ZSI, SL-ZSI, and L-ZSI, when the voltage gain and modulation index are the same.

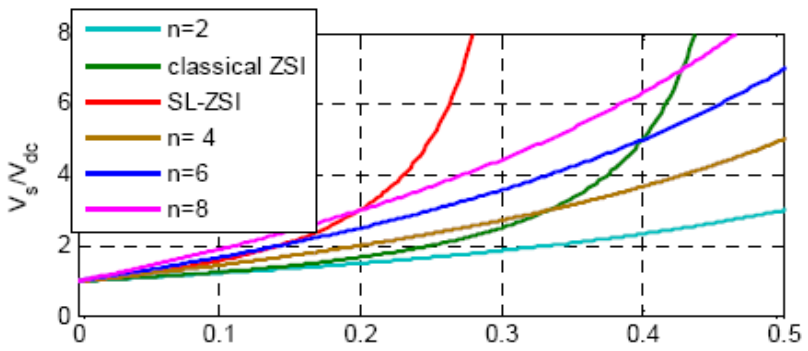

Figure 8: Switching device voltage stress for classical ZSI, SL-ZSI and L-ZSI.

Fig.9 and Fig.10 show the inductor current stress in the classical ZSI, SL-ZSI and L-ZSI. In Fig.11, it shows the inductor current stress of SL-ZSI and L-ZSI under different $\mathrm{n}$. The inductor current stress of L-ZSI is increased with the increasing of shoot-through duty ratio and the increasing of the number of inductor. Comparing Fig. 11 and Fig.8, The inductor current stress of L-ZSI is smaller than that of SLZSI, when the boost factor is equal to each other. Tab. 2 shows the inductor current stress comparison between L-ZSI and SL-ZSI, when the boost factor is equal to each other. Comparing Fig.12 and Fig.8, The inductor current stress of L-ZSI is smaller than that of the classical ZSI, when the boost factor is equal to each other. Tab. 3 shows the inductor current stress comparison between L-ZSI and the classical ZSI, when the boost factor is also equal to each other.

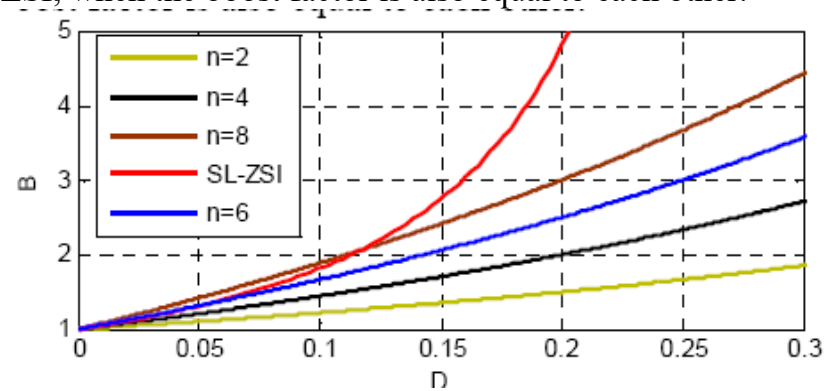

Figure 9: Inductor current stress comparison between L-ZSI and SL-ZSI. 


\section{International Journal of Science and Research (IJSR) \\ ISSN (Online): 2319-7064}

Index Copernicus Value (2013): 6.14 | Impact Factor (2014): 5.611

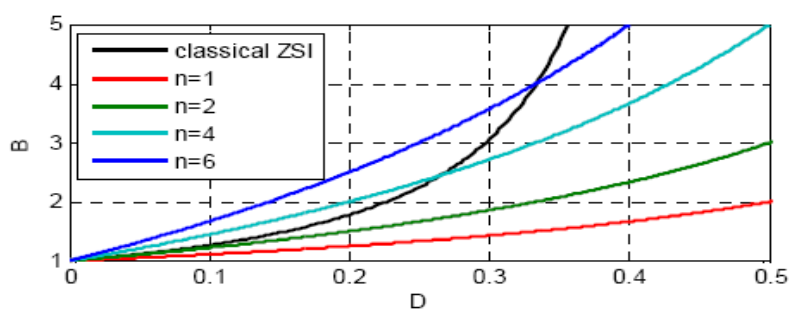

Figure 10: Inductor current stress comparison between LZSI and the classical ZSI.

Table 2: Inductor Current Stress Comparison between L-ZSI and SL ZSI

\begin{tabular}{|c|c|c|c|c|c|}
\hline \multirow{2}{*}{$\begin{array}{c}\text { Boost } \\
\text { factor }\end{array}$} & \multirow{2}{*}{$\mathrm{D}$} & \multicolumn{3}{|c|}{$\mathrm{L}$-ZSI } & \multirow{2}{*}{ SL-ZSI } \\
\cline { 3 - 5 } & & $\mathrm{n}=5$ & $\mathrm{n}=6$ & $\mathrm{n}=7$ & \\
\hline 1.5 & $1 / 11$ & $1.5 V_{d c} / R_{l}$ & & & $1.7 V_{d c} / R_{l}$ \\
\hline 2 & $1 / 7$ & & $2 V_{d c} / R_{l}$ & & $2.6 V_{d c} / R_{l}$ \\
\hline
\end{tabular}

\begin{tabular}{|l|l|l|l|l|l|}
\hline 2.5 & $3 / 17$ & & & $2.5 V_{d c} / R_{l}$ & $3.6 V_{d c} / R_{l}$ \\
\hline
\end{tabular}

Table 3: Inductor Current Stress Comparison between L-ZSI and the Classical ZSI

\begin{tabular}{|c|c|c|c|c|c|}
\hline \multirow{2}{*}{ factor } & \multirow{2}{*}{$\mathrm{D}$} & \multicolumn{3}{|c|}{ L-ZSI } & \multirow{2}{*}{ traditional ZSI } \\
\cline { 3 - 5 } & & $\mathrm{n}=3$ & $\mathrm{n}=4$ & $\mathrm{n}=5$ & \\
\hline 2 & $1 / 4$ & $2 V_{d c} / R_{l}$ & & & $2.25 V_{d c} / R_{l}$ \\
\hline 3 & $1 / 3$ & & $3 V_{d c} / R_{l}$ & & $4 V_{d c} / R_{l}$ \\
\hline 4 & $3 / 8$ & & & $4 V_{d c} / R_{l}$ & $6.25 V_{d c} / R_{l}$ \\
\hline
\end{tabular}

\section{B. Inrush Current and Voltage Overshoot Analysis}

The Z-source impedance network is the energy storage and filtering element for the ZSI. The purpose of the inductors is to limit the current ripples through the devices during boost mode with the shoot- through state. Moreover, the purpose of the capacitors is to absorb the current ripples and maintain a constant voltage to keep the ac output voltage sinusoidal.

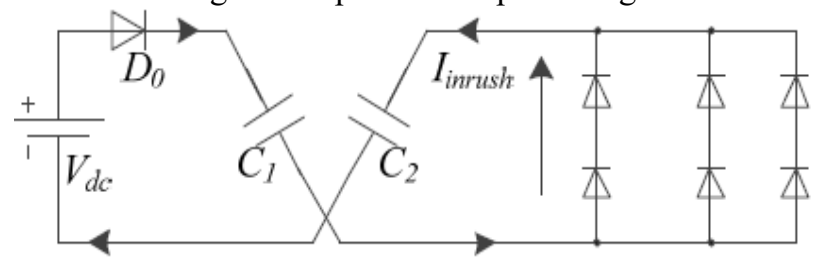

Figure 11: Startup equivalent circuit for the classical ZSI and SL-ZSI.

\section{Results}

To verify the aforementioned theoretical results, Simulation examples for L-ZSI are given using MATLAB/SIMULINK using the maximum boost control method [20].

1) $L 1=L 2=\ldots=L n-1=L n=L=45 \mu \mathrm{H}$;

2) three-phase output filter: $L f=1 \mathrm{mH}, C f=22 \mu \mathrm{F}$;

3) Switching frequency $f s=10 \mathrm{kHz}$;

4) three-phase balanced resistive load, $R l=10 \Omega$;

5) Snubber circuit: $R s=20 \mathrm{k}, C s=0.1 \mathrm{uF} / 1000 \mathrm{~V}$.

\section{A. Simulation Result I}

This example is the voltage inversion from dc $48 \mathrm{~V}$ to ac $35 \mathrm{Vrms}$ and $\mathrm{n}=2$.

Assuming $\mathrm{D}=0.2$ and $\mathrm{M}=0.8, \mathrm{~B}=1.5$.

$\mathrm{V}_{\mathrm{ac}}=\mathrm{MB} \mathrm{V} \mathrm{dc}_{\mathrm{dc}} / 2=28.8 \mathrm{~V}$

$\mathrm{V}_{\mathrm{ac}}$ is the phase peak voltage, which implies that the

Line-to-line voltage is $35 \mathrm{Vrms}$ or $50 \mathrm{~V}$ peak.

Fig. 12 shows the simulation results. From fig.12, it can be seen that the above theoretical values are quite consistent with the simulation results.
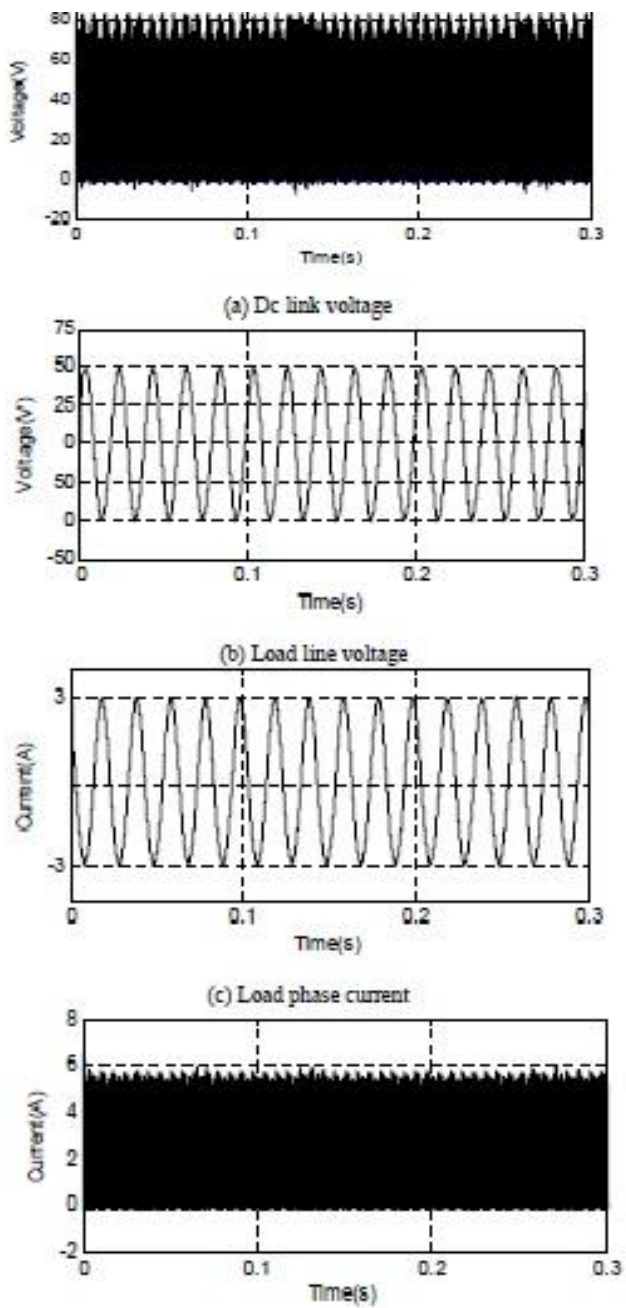

(d) Inductor current .

Figure 12: Simulation output results

\section{Conclusion}

This thesis has proposed a novel L-ZSI with improving classical ZSI. This system operates based Permanent Magnet Brushless DC motor drive. This drive system has the advantages of both PMBDCM and Z-source inverter. The system configuration, operation principle and control method have been analyzed in detail. And based on the equivalent circuits, the mathematical model has been established by state-space averaging method. Simulation results have validated the preferred features as well as the possibility of the proposed drive system. Additionally, the shortcoming of switching loss has been discussed, and a possible improvement method has been presented. Based on this

\section{Volume 4 Issue 11, November 2015}




\section{International Journal of Science and Research (IJSR) \\ ISSN (Online): 2319-7064}

Index Copernicus Value (2013): 6.14 | Impact Factor (2014): 5.611

system the inrush current at startup can be completely eliminated.

\section{Future Scope}

Trough the above analysis, it can be known that switchedinductor cell can improve the voltage gain, based on this feature the Z-source network can be extended. The operating principles as follows

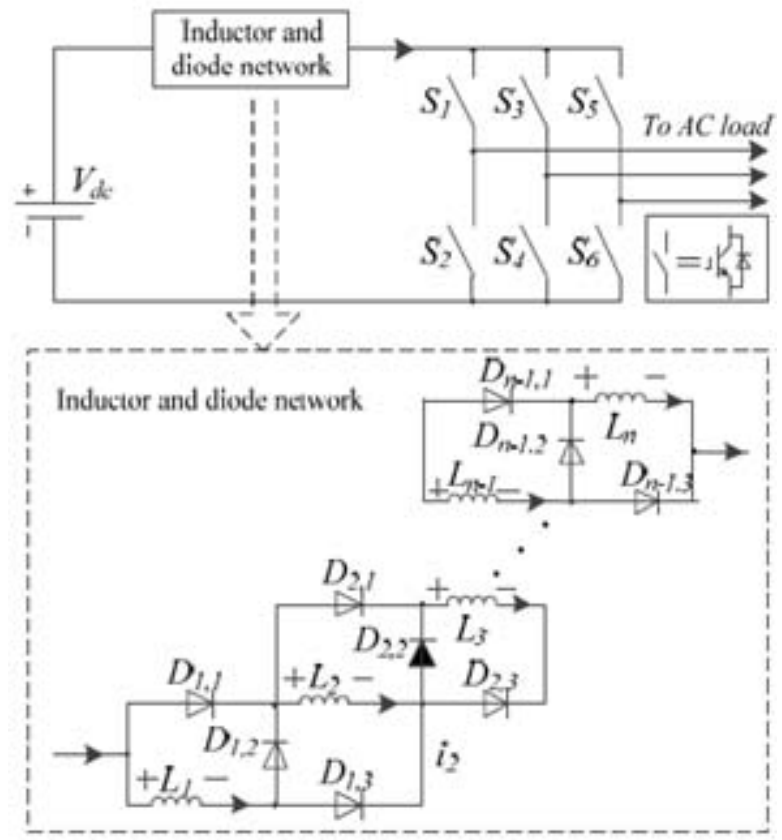

Fig. 4. L- ZSI with $\mathrm{n}$ inductors and $\mathrm{L} 1=\mathrm{L} 2=\mathrm{L} 3=\ldots=\mathrm{Ln}-1=\mathrm{Ln}$

In the non-shoot-through state, $D 1,2, D 2,2, \ldots, D n-1,2$ and $D$ n, 2 are on, while $D 1,1, D 1,3, D 2,1, D 2,3, \ldots, D$ n- $1,1, D$ n$1,3, D n, 1$ and $D$ n, 3 are off. $L 1, L 2, \ldots, L n-1$ and $L n$ are connected in series. $L 1, L 2, \ldots, L n-1$ and $L n$ transfer energy from the dc voltage source to the main circuit. The corresponding voltages across $L 1, L 2, \ldots, L n-1$ and $L n$ in this state are $V 1$ non, $V 2 \_$non, $V 3 \_$non, ..., $V \mathrm{n}-1 \_$non and $V$ n non, respectively.

$$
\begin{aligned}
& \bar{V}_{1 \_ \text {non }}+V_{2 \_ \text {non }}+\cdots+V_{n-1 \_ \text {non }}+V_{n \_ \text {non }}+V_{i}=V_{d c} \\
& V_{1 \_ \text {non }}=V_{2 \_ \text {non }}=\cdots=V_{n-1 \_ \text {non }}=V_{n \_ \text {non }} \\
& V_{1 \text { _non }}=\frac{1}{n} V_{d c}-\frac{1}{n} V_{i} \\
& V_{\text {2_non }}=\frac{1}{n} V_{d c}-\frac{1}{n} V_{i} \\
& \vdots \\
& V_{n-1 \text { non }}=\frac{1}{n} V_{d c}-\frac{1}{n} V_{i} \\
& V_{n \_ \text {non }}=\frac{1}{n} V_{d c}-\frac{1}{n} V_{i}
\end{aligned}
$$

In the shoot-through state, the inverter side is shorted by both the upper and lower switching devices of any phase leg. During the shoot-through state, $D 1,2, D 2,2, \ldots, D \mathrm{n}-1,2$ and $D$ n, 2 are off, while $D 1,1, D 1,3, D 2,1, D 2,3, \ldots, D$ n- $1,1, D$ n$1,3, D n, 1$ and $D n, 3$ are on. $L 1, L 2 \ldots L_{n-1}$ and $L_{n}$ are connected in parallel, inductors $L_{1}, L_{2} \ldots L_{\mathrm{n}-1}$ and $L_{\mathrm{n}}$ store energy is obtained.

$$
V_{1}{ }^{-}=V_{2}=\cdots=V_{n-1}=V_{n}=V_{d c}
$$

Applying the volt-second balance principle to each inductor, $B=\frac{1+(n-1) D}{1-D}$

$I_{L}=I_{1}=I_{2}=\cdots=I_{n-1}=I_{n}=\frac{D\left(n L+L_{l}\right)+L(1-D)}{R_{l} L(1-D)} V_{d c}$

$I_{l}=\frac{1+(n-1) D}{R_{l}} V_{d c}$

When the load is resistive, is concluded, as follows.

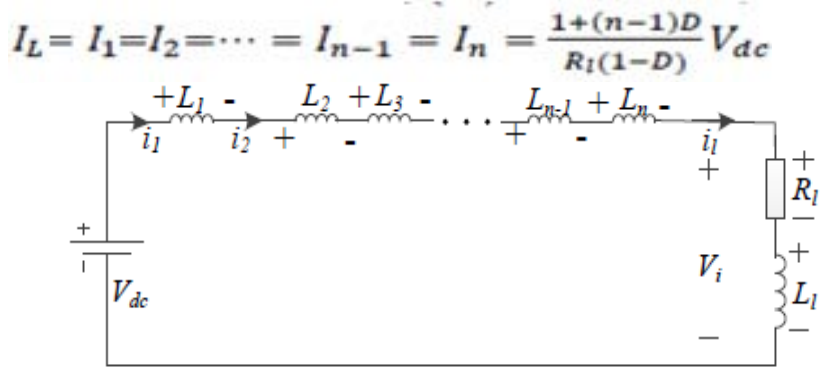

(a)

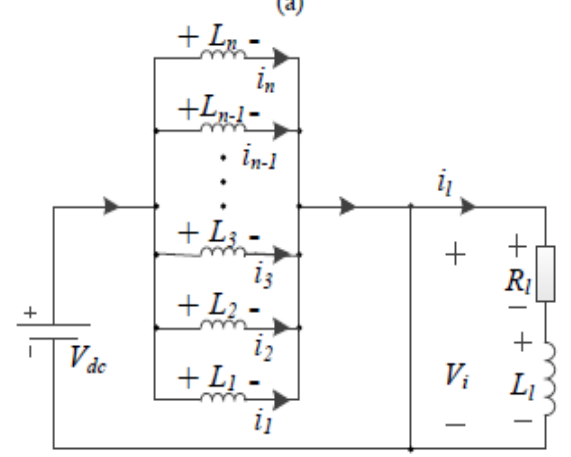

(b)

Fig.5. Operating states: (a) nonshoot-through and (b) shoot-through state.

In view of boost factor, the boost factor of L-ZSI is $[1+(\mathrm{n}$ $1) \mathrm{D}] /(1-\mathrm{D})$. When $\mathrm{n}=2$, the boost factor of L-ZSI is $(1+D) /(1-D)$ which is different from that of SL-ZSI. When $\mathrm{n}=1$, the boost factor of L-ZSI is $1 /(1-\mathrm{D})$ which is different from that of classical ZSI, and the boost voltage feature of LZSI is just like that of traditional boost converter at this time. The boost factor of L-ZSI is increased with the increasing number of inductors, and the number of inductors is not limited. The range of $\mathrm{D}$ is $[0,1)$. The boost factor of the voltage-type SL Z- Source Inverter proposed in [13] is $(1+n D) /[1-(n+2) D]$. When $n=1$, the boost factor of the voltage-type SL Z- Source Inverter is $(1+\mathrm{D}) /(1-3 \mathrm{D})$ which is the same as that of SL-ZSI, and the topology is also the same as that of SL-ZSI at this time. When $n=0$, the boost factor of the voltage-type SL Z- Source Inverter is $1 /(1-2 \mathrm{D})$ which is the same as that of classical ZSI, and the topology is also the same as that of classical ZSI at this time. In the voltage-type SL Z- Source Inverter, the number of inductors and the range of $\mathrm{D}$ are limited by $1-(\mathrm{n}+2) \mathrm{D}>0$, namely, $\mathrm{n}<1 / \mathrm{D}-2$ and $\mathrm{D}<0.5$. Through the above analysis, there is no resemblance between the proposed L-ZSI and the voltage-type SL ZSource Inverter both in principle and operation.

\section{References}

[1] N, V; Kazimierczuk, M. K.; , "Small-Signal Modeling of Open-Loop PWM Z-Source Converter by Circuit- 


\section{International Journal of Science and Research (IJSR) \\ ISSN (Online): 2319-7064}

Index Copernicus Value (2013): 6.14 | Impact Factor (2014): 5.611

Averaging Technique," Power Electronics, IEEE

Engineering College during 2013-2015. Transactions on, vol.28, no.3, pp.1286-1296, March 2013.

[2] Effah, F.B.; Wheeler, P.; Clare, J.; Watson, A.; , "SpaceVector-Modulated Three-Level Inverters With a Single Z-Source Network," Power Electronics, IEEE Transactions on, vol.28, no.6, pp. 2806-2815, June 2013.

[3] Guo, F.; Fu, L.; Lin, C.-H.; Li, C.; Choi, W.; Wang, J.; , "Development of an 85-kW Bidirectional Quasi-ZSource Inverter With DC-Link Feed-Forward Compensation for Electric Vehicle Applications," Power Electronics, IEEE Transactions on, vol.28, no.12, pp. 5477-5488, Dec. 2013.

[4] Park, K.; Lee, K.-B.; Blaabjerg, F.; , "Improving Output Performance of a Z-Source Sparse Matrix Converter Under Unbalanced Input-Voltage Conditions," Power Electronics, IEEE Transactions on, vol.27, no.4, pp.2043-2054, April 2012.

[5] Liu, X.; Loh, P. C.; Wang, P.; Han, X.; , "Improved Modulation Schemes for Indirect Z-source Matrix Converter With Sinusoidal Input and Output Waveforms," Power Electronics, IEEE Transactions on, vol.27, no.9, pp.4039-4050, Sept. 2012.

[6] Ellabban, O.; Van Mierlo, J.; Lataire, P.; , "A DSPBased Dual-Loop Peak DC-link Voltage Control Strategy of the Z-Source Inverter," Power Electronics, IEEE Transactions on, vol.27, no.9, pp.4088-4097, Sept. 2012.

[7] Yan Zhou; Liming Liu; Hui Li; , "A High-Performance Photovoltaic Module-Integrated Converter (MIC) Based on Cascaded Quasi-Z-Source Inverters (qZSI) Using eGaN FETs," Power Electronics, IEEE Transactions on, vol.28, no.6, pp. 2727-2738, June 2013.

[8] Poh Chiang Loh; Feng Gao; Pee-Chin Tan; Blaabjerg, F.; , "Three-level ac-dc-ac Z-source converter using reduced passive component count," IEEE Trans. Power Electron., vol. 24, no. 7, pp. 1671-1681, Jul. 2009.

[9] Yu Tang; Shaojun Xie; Chaohua Zhang; Zegang Xu; , "Improved Z-source inverter with reduced capacitor voltage stress and soft-start capability," IEEE Trans. Power Electron., vol. 24, no. 2, pp. 409-415, Feb. 2009.

[10]F. Z. Peng; , “Z-source inverter," IEEE Trans. Ind. Appl., vol. 39, no. 2, pp. 504-510, Apr. 2003.

[11] Gajanayake, C.J. ; Fang Lin Luo; Hoay Beng Gooi; Ping Lam So; Lip Kian Siow; , "Extended boost Z-source inverters," IEEE Trans. Power Electron., vol. 25, no. 10, pp. 2642-2652, Oct. 2010.

[12] Miao Zhu; Kun Yu; Fang Lin Luo; , "Switched Inductor Z-Source Inverter," Power Electronics, IEEE Transactions on, vol.25, no.8, pp. 2150- 2158, Aug. 2010.

[13]Li, D.; Loh, P. C.; Zhu, M.; Gao, F.; Blaabjerg, F.; , "Generalized Multicell Switched-Inductor and Switched-Capacitor Z-Source Inverters," Power Electronics, IEEE Transactions on, vol.28, no.2, pp.837848, Feb. 2013.

\section{Author Profile}

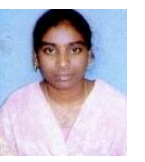

Dubasi Nirosha received the B.Tech degree in Electrical and Electronics Engineering from V. R. Siddhartha Engineering College Vijayawada, during 2010-2013. She is doing her M.Tech degree in Aditya 